\title{
A EDUCAÇÃO FÍSICA EM CICLOS DE APRENDIZAGEM: CONTEXTUALIZANDO A POLÍTICA EDUCACIONAL DO MUNICÍPIO DO RECIFE
}

\author{
Eliene Lacerda Pereira \\ Secretaria Municipal de Educação de Goiânia, Goiás, Brasil \\ Marcílio Souza Júnior \\ Universidade de Pernambuco, Recife, Pernambuco, Brasil
}

\begin{abstract}
Resumo
Este artigo discute a implementação do sistema de ciclos na Rede Municipal de Ensino do Recife - RME-REC. Procura-se discutir como a Educação Física - EF está inserida no contexto das políticas educacionais da RME-REC. Analisam-se as políticas educacionais no que se refere aos ciclos de aprendizagem e à Educação Física. Esta pesquisa se caracteriza por um estudo qualitativo e documental tendo como fonte os documentos oficiais da Secretaria de Educação, Esporte e Lazer do Município do Recife. Aponta-se o reconhecimento pela Secretaria da necessidade de espaços para discussão e trocas de experiências, o envolvimento do coletivo na elaboração da proposta e a participação ativa da Educação Física na construção desta política.
\end{abstract}

Palavras-chave: Política Educacional - Ciclos de Aprendizagem - Educação Física

\section{Introdução}
o pesquisar sobre a Educação Física - EF nos ciclos de aprendi- - zagem, em particular, na Secretaria de Educação, Esporte e La- zer - SEEL - da Rede Municipal de Ensino do Recife RME-REC, torna-se necessário compreender as suas políticas educacionais.

A implementação dos ciclos, como proposta de ensino em escolas públicas e particulares do Brasil, apresenta-se como uma tentativa baseada na Lei de Diretrizes e Bases da Educação Nacional - LDB 9394/96, de superar concepções fragmentadas e padronizadas de educação. Isto se deve à grande influência de políticas de esquerda na década de 1990 no país com novas propostas na intenção de alavancar o ensino no Brasil.

Tendo em vista a política educacional na RME-REC, a Educação Física é entendida como componente curricular igual aos demais com- 
ponentes, possuindo responsabilidades na formação dos estudantes. Atualmente, nas escolas do município do Recife que se organizam em ciclos de aprendizagem, a prática pedagógica da Educação Física procura se adaptar para atender à proposta de ciclos.

Diante desta realidade, a investigação parte da seguinte inquietação: Como a Educação Física está inserida no contexto das políticas educacionais da RME-REC? Este artigo tem por objetivo analisar as políticas educacionais da SEEL do Recife quanto à implementação da proposta de ciclos de aprendizagem frente ao componente curricular Educação Física.

Esta pesquisa se caracteriza por um estudo qualitativo documental que teve como fonte os documentos oficiais da SEEL, assim como procurou fazer a revisão de literatura sobre as produções acerca da Educação Física frente à política dos ciclos de aprendizagem.

Os documentos analisados foram: 1 - Tempos de Aprendizagem (RECIFE, 2003), documento que orienta a implementação do currículo por ciclos de escolarização, composto de sua fundamentação, normatização, princípios e relatos de implementação; 2 - Educação Física Escolar - uma proposta pedagógica (Coletivo de Professores de Educação Física da Rede de Educação Municipal do Recife, 2005), documento específico da Educação Física que delimita competências e conteúdos diante de quatro eixos temáticos da Cultura de Movimento e os distribui nos ciclos de aprendizagem, segundo o trabalho resultante dos professores da Rede municipal em livro autorizado pela para publicação pela Prefeitura; 3 - Educadores em Rede (Recife, 2008), documento composto de textos que expressam a Política de Formação Continuada da Secretaria de Educação, Esporte e Lazer - SEEL, referente ao quadriênio 2005-2008, que tem como objetivo contribuir com um modelo de educação democrática voltada para a cidadania plena e participativa.

Para a analisarmos os documentos utilizamos a análise de conteúdo, que segundo Bardin (2004) define a análise documental como uma operação ou um conjunto de operações visando representar o conteúdo de um documento sob uma forma diferente da original, com o objetivo de facilitar, num estágio seguinte, a sua consulta e referenciação. Esta análise é uma fase preliminar de um serviço de documentação, trabalha com documentos, por classificação e indexação, e tem por objetivo a representação condensada da informação para consulta e armazena- 
mento. consultar e armazenar. Os documentos constituem uma fonte confiável e rica, podendo servir de base para diferentes estudos.

\section{Os ciclos e as políticas educacionais}

Os ciclos de aprendizagem foram implantados com o objetivo de superar o sistema seriado e, com eles, as políticas educacionais voltadas à organização curricular. Com governos de esquerda assumindo prefeituras em várias cidades do Brasil no final dos anos 1990, surgiram novas propostas educacionais que foram ganhando força, assim como propiciaram a participação da sociedade participação na construção destas.

Para Freitas (2003, p. 70), “os ciclos não devem ser implantados como política pública que determine em massa sua adoção". O autor sugere que o caminho mais adequado é

Do convencimento por indução, a partir de experiências bemsucedidas apoiadas pelos governos, envolvendo pais e professores no processo. Não se deve fazer experimentos com redes inteiras. As escolas devem ter autonomia para optar pela introdução da organização ciclada em seu interior e serem apoiadas nessa decisão (FREITAS, 2003, p. 70).

Como toda proposta, é preciso considerar posicionamentos a favor e contra a organização do ensino em ciclos. Mainardes (2001) destaca pontos relevantes nessa proposta, tais como: a necessidade de se repensar a escola, suas práticas avaliativas, conteúdos curriculares e o trabalho pedagógico; a agilidade no fluxo escolar, o descongestionando do sistema; a possibilidade do ingresso da população que não tem acesso à escola; a garantia aos alunos de um maior tempo de permanência na escola. Esta organização exige maiores recursos para a educação e sugere mudanças na expectativa das famílias em relação ao processo educativo, como a superação da preocupação com a nota e a aprovação e a observância em relação ao conhecimento que as crianças adquirem na escola.

O autor ressalta implicações contra os ciclos como: a sua utilização como solução formal para diminuir os índices de repetência, sem a devida preocupação em elevar a qualidade do ensino; a descontinuidade de políticas educacionais; a falta do trabalho coletivo e indefini- 
ção do projeto pedagógico. Esses aspectos dificultam o desenvolvimento dessa proposta pedagógica correndo o risco de torná-la inviável.

Na proposta de ciclo como política educacional, Krug (2001) considera de extrema relevância, no desenvolvimento dos ciclos, o envolvimento dos que conduzem à escola: professores e pais. Os professores porque refletem diretamente no processo de ensino-aprendizagem e os pais porque é preciso envolvê-los no processo de implementação para que possam compreender o processo formativo dos ciclos e deixar de ver a escola formalmente, ou seja, como uma instituição com estruturas e organizações de tempos e espaços rígidas.

A proposta de Freitas (2003) é a de que se pode intervir no processo educacional por meio de movimentos sociais e associados. Estes movimentos permitem a abertura de espaços de resistência e mobilização no interior das instituições. O autor enfatiza que os ciclos e a escola de tempo integral são ferramentas importantes na luta por uma transformação social frente às perversas condições do sistema.

Mainardes (2007) adota a abordagem do sistema de ciclos e, mesmo com críticas a este, o autor considera que eles podem orientar análises da trajetória de políticas e programas educacionais, sem incorrer em limitações de teorias que ora atendem às determinações do Estado, ora são localizadas como políticas imediatas. $\mathrm{O}$ autor demarca três contextos: o da influência, o de produção do texto da política e o da prática. O ciclo propõe que sejam analisados o contexto dos resultados e o contexto da estratégia política que aponta atividades necessárias para lidar com eventuais desigualdades desencadeadas na implementação desse sistema.

Vemos enfim que vários autores chamam a atenção para considerações políticas e sociais na implementação da proposta de ciclos, destacando a necessidade de se repensar o âmbito educacional em conjunto com a sociedade.

\section{A organização da educação escolar em ciclos no município do Recife}

$\mathrm{Na}$ implementação dos ciclos de aprendizagem na cidade do Recife, a gestão da Prefeitura era do Partido dos Trabalhadores - PT. Uma gestão autodenominada democrático-popular, que viabilizou a participação da comunidade em plenárias do Orçamento Participativo e mo- 
bilizou conferências municipais, proporcionando à educação um momento particular de discussão (SOUZA JÚNIOR, 2007a).

Com base no documento "Tempos de Aprendizagem" (PREFEITURA DO RECIFE, 2003), as políticas adotadas pela RME-REC, inseridas no contexto dos ciclos de aprendizagem, estão fundamentadas na possibilidade político-pedagógica da ação-cidadã na perspectiva da construção coletiva, da qualidade social, de formas de viver e conviver para a cidadania, com o fito de transformar a escola em espaço de experiências.

Neste documento a proposta de implementação dos ciclos de aprendizagem se configura enquanto política com a regulamentação dos ciclos de aprendizagem e da organização da escola em ciclos com o parecer 02/2001 do Conselho Municipal de Educação da Prefeitura do Recife. Implantada em 2001, a política dos ciclos de aprendizagem representam um projeto histórico de base socialista, que expressam uma proposta de educação referenciada nos princípios de inclusão, igualdade, autonomia, integridade e diversidade. Eles têm como base a reorganização do tempo, do espaço e da prática pedagógica, num processo contínuo, respeitando a diversidade e os diferentes tempos dos alunos para aprender.

Neste documento, a escola deve relacionar as aprendizagens com as práticas sociais e todos os educadores devem estar comprometidos com a transformação social, repensando sua visão de mundo, planejando, agindo e contribuindo para a integração coletiva da escola nesses novos tempos. Desse modo, a escola passa a ter condições de assegurar a construção da identidade cidadã e o sujeito aprende a valorizar sua cultura enfrentando desafios, construindo seu caminho e aprendendo a se relacionar com os outros.

\section{O que muda no ensino com a política dos ciclos?}

Diante das vivências escolares, com as novas possibilidades de organização do trabalho pedagógico da escola, as dificuldades encontradas pelos estudantes não são mais problema exclusivo de um professor, mas de todo o coletivo escolar. Este coletivo discute o processo de ensino e aprendizagem dos alunos e apresenta propostas para que este aprenda, superando suas próprias limitações. Está é uma característica que se distingue do ensino seriado, no qual não se trabalha a partir das dificuldades individuais, mas da universalização do saber, 
o que ocasionou os altos índices de reprovação e evasão escolar.

Para o Coletivo de Autores (2009), os ciclos superam a estrutura seriada com princípios da lógica formal, favorecendo a diversidade, numa estrutura espiralada oriunda da lógica dialética, buscando na educação transformadora uma contribuição para a superação da sociedade capitalista.

Essa forma de racionalidade requer não apenas uma mudança nas formas de pensar a realidade, mas pede, fundamentalmente, uma mudança correspondente em nossas ações, a partir de princípios em que o importante é observar uma transição crítica do individualismo para a cooperação, da quantidade para a qualidade, da dominação para a parceria, sem escamotear, porém, os antagonismos presentes na sociedade de classes (MUÑOZ PALAFOX, 2001, p. 159).

Os ciclos se apresentam como uma possibilidade de repensar o ensino, redimensionando as organizações da escola. Neste contexto, a implementação dos ciclos de aprendizagem requer mudanças estruturais e políticas, que permitam aos estudantes a oportunidade de aprender de acordo com o seu ritmo e tempo de aprendizagem.

Fundamentado em estudos de Souza Júnior (2007b) a respeito das mudanças no sistema de ensino, a RME-REC tomou iniciativas para que estas não fossem apenas de nomenclatura, reconhecendo a proposta no do Conselho de Ciclo e dos Espaços Ampliados de Aprendizagem

Com a política de ciclos, redimensiona-se o quantitativo de professores, diminui-se o número de alunos por sala, promove-se a participação intensa dos professores, gerando a responsabilidade de todo o coletivo. E é através de momentos específicos, como o planejamento, que os professores se reúnem para discutir e apresentar alternativas com a intenção de solucionar os problemas encontrados diariamente, $\mathrm{o}$ que não acontece, com esta intenção, no sistema seriado.

Segundo Machado (2007), os ciclos de aprendizagem se organizam baseados nas aprendizagens de Philippe Perrenoud. Segundo esse autor (2004, p. 35), o sistema de ciclos não é novo, o que se torna novo é o grande número de países que vivenciaram ou estão vivenciando os ciclos plurianuais em todo o sistema educacional. Em uma definição mais ousada "um ciclo de aprendizagem poderia servir de quadro inte- 
grador e de ponto de apoio a uma evolução do ofício de professor, dos programas e das formações escolares, da avaliação e da luta contra as desigualdades".

Perrenoud (2004) assinala, ainda, que um ciclo de aprendizagem é um ciclo de estudos no qual não há mais reprovação, mas chama a atenção para a necessidade de se ir além, pois não é possível ater-se somente à eliminação da reprovação para cessar o fracasso escolar, já que os ciclos apresentam características interessantes na esperança de uma nova pedagogia.

Os ciclos vêm equiparar a defasagem idade/série, com base nos dados do Instituto de Estudos e Pesquisa - INEP. O índice elevado de defasagem foi um dos motivos que contribuiu para a multiplicação de propostas de organização escolar em ciclos, inclusive na realidade da cidade do Recife.

Nesta nova estruturação da proposta de ciclos, Nedbajluk (2006) define que os ciclos de aprendizagem:

Têm seu eixo organizador situado preponderantemente em torno dos resultados esperados, isto é, nas aprendizagens obtidas. É necessário que o aluno adquira certos conhecimentos e desenvolva certas competências, estabelecidas como mínimos essenciais e, portanto, se constituem como condição ou pré-requisito para a progressão a um nível superior, a graus de aprofundamento e complexidade crescentes do conteúdo. Neste caso a flexibilização recai nos tempos despendidos pelo estudante, pois dependendo de suas capacidades pessoais, poderá progredir de um grau para outro ao seu próprio ritmo, em tempos diferentes de seus pares (NEDBAJLUK, 2006, p. 251).

O currículo organizado por ciclos aprendizagem procura reorganizar os tempos e espaços. A Prefeitura da cidade do Recife - PCR distribuiu-o em quatro ciclos no ensino fundamental: $1^{\circ}$ ciclo crianças de 6 a 8 anos; $2^{\circ}$ Ciclo 9 e 10 anos; $3^{\circ}$ Ciclo 11 e 12 anos e $4^{\circ}$ Ciclo com crianças a partir de 13 anos.

Machado (2007, p. 115), ao estudar as representações sociais dos professores da Rede Municipal do Recife que trabalham com os ciclos de aprendizagem, bem como suas implicações para as práticas educativas, identifica que quando os alunos do curso de Pedagogia chegam para desenvolver o estágio curricular nas escolas "não têm conseguido 
entender o que diferencia ciclos de séries ou quais as razões que levam muitas vezes os professores a tratar as duas formas de organização das turmas como sinônimos".

Com a implementação de uma nova política de Rede, surgem questionamentos, sentimento de insegurança e dúvidas frente às concepções pedagógicas, movimento natural durante as primeiras experiências de uma política educacional. No entanto, em razão das inquietações resultantes do primeiro ano de funcionamento dos ciclos, foi realizada uma primeira avaliação com a intenção de ouvir os professores sobre suas experiências pedagógicas (RECIFE, 2003).

Para que o funcionamento da proposta se materialize e tenha qualidade é necessário o planejamento coletivo do trabalho pedagógico entre os professores, possibilitando a interdisciplinaridade e participação ativa nas atividades escolares que extrapolem a sala de aula.

Como ação desenvolvida da proposta de ciclos, a RME-REC tem investido na continuidade no processo de formação dos educadores com caráter coletivo que supere a formação como eventos isolados.

A formação passa a ser considerada como política de desenvolvimento institucional que, oportunizando o aprendizado de todas as educadoras e de todos os educadores da Rede, quer fazê-lo na direção de mudanças sociais significativas no contexto da ação educacional, a partir da perspectiva dialógica proporcionada pelo trabalho em grupo. Tais mudanças pressupõem a ressignificação de práticas pedagógicas e o aperfeiçoamento permanente. Estes são vistos, não apenas como direito de todos os agentes da Educação, mas também como instrumento de qualificação dos processos de ensino e aprendizagem (RECIFE, 2008, p. 17).

No documento "Educadores em Rede" (RECIFE, 2008) a perspectiva da proposta de formação continuada é orientada pelo compromisso com as políticas educacionais da SEEL, destacando a importância de outros instrumentos e atores para que estas ações se efetivem como: a avaliação, o apoio das salas de leitura o fortalecimento do coletivo de professores e o espaço de planejamento.

A formação de professores por meio da práxis pedagógica deve possibilitar um autêntico diálogo com a cooperação e a solidari- 
edade entre as culturas, o respeito à identidade de cada uma e seu direito à sobrevivência e ao florescimento; esse modelo multicultural também defende o máximo respeito à autonomia $\mathrm{e}$ à dignidade dos indivíduos (SOUZA, 2006, p. 48).

O documento indica que após o levantamento pelo grupo de trabalho de formação continuada foi identificado que os espaços para a formação existentes - os estudos intensivos semestrais; os encontros pedagógicos mensais para $3^{\circ}$ e $4^{\circ}$ ciclos; a capacitação para professores de escolas profissionalizantes e de educação infantil; e a possibilidade de participação em congressos, seminários, palestras e cursos de graduação e pós-graduação - eram escassos quanto ao tempo/espaço. Somava-se a isso a exclusão de alguns segmentos de profissionais envolvidos na educação escolar, a falta de articulação entre as instâncias de formação, a pouca ênfase dada às necessidades específicas e a desinformação quanto à participação de eventos fora da Secretaria.

O grupo propôs diretrizes políticas à a práticas de formação que estivessem articuladas num processo inclusivo e contínuo de reflexão e reconstrução coletiva, concretizado em palestras, mesas e discussões específicas com especialistas em uma reflexão constante sobre as práticas no interior da escola.

A política de formação continuada procurou se pautar pela articulação com os diversos segmentos do trabalho escolar e pela promoção de transformações qualitativas nas concepções e no fazer pedagógico das educadoras e dos educadores (RECIFE, 2008, p.24).

No documento "Educadores em Rede" (RECIFE, 2008) Araújo e Amorim (2008) ressaltam que se devem dar condições sociais de ensino e de trabalho aos professores, sendo que a realização das atividades resulta do enfrentamento da discussão sobre o cotidiano escolar, as condições de trabalho, a visão de mundo e o conhecimento epistemológico sobre o objeto de ensino e aprendizagem.

A equipe gestora aponta desafios que devem permanecer em sua proposta como: a necessidade de garantir o diálogo entre educadores, através de mecanismos de escuta; a instituição de mecanismos de avaliação; a familiarização dos educadores e da Rede com os princípios 
da organização do ensino em ciclos de aprendizagem, garantindo a integridade da proposta e desta com os processos de formação.

\section{A educação física em ciclos de aprendizagem}

A política de formação também se reflete na disciplina Educação Física, assim como em toda Rede. Este componente curricular tem seus momentos de questionamentos, de críticas, de aflições e de insegurança diante da nova organização pedagógica.

No documento "Educadores em Rede" (RECIFE, 2008), França (2008) observa que o processo de formação continuada dos professores de Educação Física incorpora novas teorias em função de experiências construídas numa relação dialógica de sua intervenção, fundamentada em três princípios da ação-reflexão-ação: diversidade, singularidade e interdisciplinaridade.

Com esse suporte teórico-prático, na dança das determinações de modelos e códigos impostos e/ou estereotipados, o jogo das relações se realiza numa escola viva e dinâmica que busca nas formas da ginástica superar equívocos e nas possibilidades da luta manter resistências visando enfrentamento e rupturas de concepções reducionistas e fragmentadas e na superação de uma prática de esporte excludente, fragmentado e alheio à sensibilidade do jovem estudante. Esta é, sem dúvida, uma virada que a Educação Física, enquanto componente curricular busca: materializar práticas dialogando com outras formas de linguagem escolar, como por exemplo, a linguagem matemática, a linguagem histórica, a linguagem geográfica, a linguagem artística, a linguagem inglesa, dentre outras (FRANÇA, 2008, p 229).

Refletir sobre suas práticas e transformá-las é a proposta possível para vislumbrarmos uma Educação Física que participe e esteja presente na proposta dos ciclos de aprendizagem. A partir do momento em que a Prefeitura do Recife configura os ciclos como uma política educacional, a Educação Física não foge a este processo, os professores participam da formação continuada voltada para a construção de diretrizes e princípios da Educação Física.

Esta participação resultou num documento de proposição pedagó- 
gica que foi publicado. Este documento teve a contribuição de convidados do Encontro Pedagógico Mensal - EPM - sobre o processo de formação continuada, promovido pela Secretaria de Educação no período de 2002-2004, que discutiu temas relacionados a educação física escolar, corpo, cultura de movimento, jogo, esporte, dança, ginástica, treinamento escolar, capoeira, além de nos permitir uma visualização da política curricular dos ciclos na Rede e a relação da Educação Física neste contexto com a produção do grupo de professores de Educação Física participantes do EPM.

Uma intencionalidade pedagógica para com os conteúdos, objetivos, habilidades e disciplinas pode partir do professor, mas não pode encerar-se nele mesmo. Ela deve chegar de maneira propositiva e confrontar-se com as características coletivas e individuais dos alunos, permitindo uma heterogeneidade e diversidades dos ritmos e formas de aprendizagem buscando construir uma lógica dialética para estruturação do pensamento (SOUZA JÚNIOR, 2007a, p. 113).

No documento "Educação Física Escolar - uma proposta pedagógica" o coletivo de professores de Educação Física da Rede de Educação Municipal do Recife (2005) reconhece que o trabalho docente deve estar voltado para a aprendizagem de regras de convívio, para a construção dos vínculos sociais, valores éticos e para a garantia dos direitos sociais com o objetivo de construir uma formação transformadora e emancipatória.

Partindo dessa compreensão, reconhecemos a Educação Física como uma prática pedagógica que possibilita sintetizar e sistematizar representações do mundo no que concerne à produção histórica e social de algumas das dimensões, elaborações, manifestações da cultura humana, em contextos específicos, tais como: jogos, esportes, ginásticas, lutas e dança. Dispondo da sua intencionalidade, o ser humano, em interação com os outros e com a natureza, produz, expressa e incorpora essa cultura em forma de signos, idéias, conceitos e ações nas quais interpenetram dialeticamente as intenções dos próprios homens e a realidade social (COLETIVO DE PROFESSORES DE 


\section{EDUCAÇÃO FÍSICA DA REDE DE EDUCAÇÃO MUNICI- PAL DO RECIFE, 2005, p. 223).}

A partir do trabalho de formação realizado com o coletivo de professores de Educação Física da RME-REC (2005), o componente curricular dessa disciplina se estrutura nos $3^{\circ}$ e $4^{\circ}$ ciclos, fundamentando-se nos eixos temáticos da cultura de movimento: a) Jogo: elementos lúdicos e simbólicos; b) Esporte: elementos institucionalizados; c) Dança e manifestações rítmicas; d) Ginástica e qualidade de vida coletiva. A disciplina tem ainda como conteúdos: a) Tipologia; b) Fundamentos de regulação; c) Fundamentos gestuais e de organização; d) Princípios de realização; e) Temas históricos e sociais. Esta organização está presente na caderneta escolar de todas as escolas.

A Educação Física não consegue inserir-se, pedagogicamente, no currículo ciclado das escolas da prefeitura. Mas não pelo fato de já se achar no ciclo, mesmo antes da implementação desse, já que vivia certa flexibilização no tratamento dos saberes escolares e sim, devido a sua desestruturação pedagógica em relação a esses saberes, a sua desarticulação com o cotidiano da escola, a começar pelo entendimento de seu próprio papel pedagógico na escola (SOUZA JÚNIOR, 2007b, p. 93).

A Educação Física deu saltos qualitativos em relação à realidade brasileira e à própria realidade municipal, afirma Souza Júnior (2007b), uma vez que contribuiu para a conquista de uma isonomia frente às outras áreas e frente à política curricular da SEEL.

Mesmo com fragilidades durante a gestão no que se refere à política educacional como um todo, na concepção pedagógica dos docentes e na prática pedagógica dos professores, avanços são reconhecidos ao sistema de ciclos quanto ao processo de ensino-aprendizagem.

\section{Considerações finais}

Com base nas análises realizadas dos documentos da SEEL, assim como nos estudos de revisão de literatura, podemos levantar algumas considerações frente aos ciclos de aprendizagem na Rede Municipal de Ensino do Recife. Os ciclos surgem com o objetivo de diminuir o 
fracasso escolar e equiparar a defasagem idade/série frente aos altos índices de retenção. Este foi o motivo que estimulou a concretização dessa proposta em diversas realidades de ensino, inclusive na cidade do Recife com a implementação dos ciclos de aprendizagem em toda Rede em 2001.

Os ciclos de aprendizagem se organizam, na Rede Municipal de Ensino do Recife, baseados nas aprendizagens de Philippe Perrenoud e trazem uma nova concepção de ensino com mudanças no currículo. $\mathrm{O}$ currículo, por ciclos, procura reorganizar os tempos e os espaços escolares, uma vez que é a escola quem deve se adequar aos diferentes estudantes e não o contrário.

$\mathrm{Na}$ realidade da Rede Municipal, o $1^{\circ}, 2^{\circ}, 3^{\circ}$ e $4^{\circ}$ ciclos de aprendizagem, que correspondem ao ensino fundamental, foram implantados em todas as escolas de uma única vez. As transformações com a implementação de uma nova concepção de ensino alteram o cotidiano da escola e representam novas possibilidades no processo de ensinoaprendizagem, além de influírem, tanto no ciclo enquanto organização escolar, quanto no ciclo enquanto organização do pensamento.

Destacamos a presença e a participação ativa dos professores de Educação Física na construção da proposta pedagógica para essa disciplina, após a implementação dos ciclos de aprendizagem. Atendendo a esta demanda, a proposta de formação continuada apresentada pela Secretaria de Educação, Esporte e Lazer tem o propósito de oferecer alternativas e encontrar soluções para questões que envolvam cada componente e a escola.

Críticas sobre as políticas educacionais são frequentes, principalmente quanto à não institucionalização das propostas como políticas e quanto à continuidade dos projetos. Muda-se a gestão e em muitos casos, por questões partidárias, o processo se fragmenta e consequentemente modifica-se a concepção de ensino. Não é o caso da cidade do Recife, na qual na última eleição, o Partido dos Trabalhadores conseguiu se reeleger e dar continuidade aos projetos e propostas da Rede.

A política de ciclos proposta pela Secretaria de Educação, Esporte e Lazer da cidade do Recife ressalta a necessidade de espaços que promovam debates, discussões, estudos e trocas de experiências a partir da realidade de cada professor e da escola. Estes espaços têm a formação continuada como eixo articulador destes momentos.

É importante para a continuidade dos ciclos o envolvimento do coletivo na construção e reconstrução da proposta, na organização do 
trabalho pedagógico da escola, desde a participação no projeto político pedagógico, no planejamento coletivo, no planejamento por componente curricular, o planejamento individual - hora atividade - do(a) professor até a participação no conselho de ciclos. Estes são momentos imprescindíveis que devem ser garantidos pela Rede e constantes da rotina da escola.

Physical Education in learning cycles: contextualizing the educational policy of the city of Recife

\begin{abstract}
This article discusses the implementation of cycle systems in the Municipal School System of Recife - RME-REC. The aim is to discuss how Physical Education - PE is inserted in the context of the educational policies of RME-REC. The objective was to analyze the educational policies in terms of learning cycles and Physical Education. This research characterizes itself by a qualitative and documental study, utilizing official documents of the Department of Education, Sports and Leisure of the city of Recife. It is important to state that the department recognizes the necessity for spaces for discussions and experience exchange, the involvement of collectivity in the elaboration of the proposal and the active participation of Physical Education in the construction of this politics.
\end{abstract}

Keywords: Educational Policy - Learning Cycle - Physical Education

La educación física en ciclos de aprendizaje: contextualización de la política educativa de la ciudad de Recife

\title{
Resumen
}

Este artículo aborda el despliegue de los ciclos en el RME-REC. La problemática és ¿ Cómo la educación física se coloca en el contexto de las políticas educativas de RME-REC $i$ ? El objetivo fue analizar las políticas educativas con respecto a los ciclos de aprendizaje y la educación física. Esta investigación se caracteriza por un estudio cualitativo y el documento de la fuente en los documentos oficiales del Departamento de Educación, Deporte y Ocio en la ciudad de Recife. Señala el reconocimiento de la necesidad de espacio de oficina para el debate y el intercambio de experiencias, la participación colectiva en la preparación de la propuesta y la participación activa de la Educación Física en la construcción de esta política.

Palabras clave: Política Educativa - Ciclos de Aprendizaje - Educación Física

\section{Referências}

ARAÚJO, M. J. V.; AMORIM, R. M. Formação Continuada e a Prática Pedagógica dos (as) Professores (as) alfabetizadores (as): desafios e perspectivas para um novo tempo. In: RECIFE, Prefeitura do. Secretaria de Educação. Diretoria Geral de Ensino e Formação Docente. 
Educadores em Rede: articulando a diversidade e constituindo singularidades. Recife, 2008, p. 149-156.

BARDIN, L. Análise de conteúdo. -3.ed. Lisboa: Edições 70, 2004.

COLETIVO DE AUTORES. Metodologia do ensino da educação física. 2.ed. rev. São Paulo: Cortez, 2009.

COLETIVO DE PROFESSORES DE EDUCAÇÃO FÍSICA DA REDE DE EDUCAÇÃO MUNICIPAL DO RECIFE. Educação Física Escolar - uma proposta pedagógica. In: SOUZA JÚNIOR, M. (org.) et al. Educação Física Escolar: teoria e política curricular, saberes e proposta pedagógica. Série Educação e Cultura. Recife: EDUPE, 2005, p. 219-231.

FRANÇA, T. Formação Continuada - Construção Permanente de Saberes: diversidade e singularidades na Educação Física da Rede Municipal de Ensino. In: RECIFE, Prefeitura. Secretaria de Educação. Diretoria Geral de Ensino e Formação Docente. Educadores em Rede: articulando a diversidade e constituindo singularidades. Recife, 2008 .

FREITAS, L. C. Ciclos, seriação e avaliação: confronto de lógicas. São Paulo: Moderna, 2003.

MACHADO, L. Eles "Passam de Rolo" e Ficam Cada Vez Mais Analfabetos: discutindo as representações sociais de ciclos de aprendizagem entre professores. Psicologia da Educação, São Paulo, 24, $1^{\circ}$ sem. de 2007, p. 111-128.

MAINARDES, J. A Organização da Escolaridade em Ciclos: ainda um desafio para os sistemas de ensino. In: FRANCO, C. (org.). Avaliação, ciclos e promoção na educação. Porto Alegre: Artmed Editora, 2001, p. 35-54.

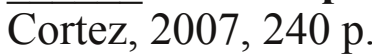

. Reinterpretando os ciclos de cprendizagem. São Paulo:

MUÑOZ PALAFOX, G. H. Intervenção político-pedagógica: a necessidade do planejamento do currículo e da formação continuada para a transformação da prática educativa. Tese Doutoral. PUC. São Paulo, 2001. 
NEDBAJLUK, L. Formação por Ciclos. Educar, Curitiba, n. 28, p. 247-261, Editora UFPR. 2006.

PERRENOUD, P. Os ciclos de aprendizagem: um caminho para combater o fracasso escolar. Porto Alegre: Artmed, 2004.

RECIFE, Prefeitura. Tempos de aprendizagem: identidade cidadã e organização da educação escolar em ciclos. Recife: A Secretaria: Ed. Universitária da UFPE, 2003.

RECIFE, Prefeitura. Educadores em Rede: articulando a diversidade e constituindo singularidades. Diretoria Geral de Ensino e Formação Docente, 2008.

SOUZA, J. F. Prática pedagógica e formação de professores. Ensaio para concorrer ao Cargo de Professor Titular do Departamento de Métodos e Técnicas de Ensino do Centro de Educação da Universidade Federal de Pernambuco: 2006.

SOUZA JÚNIOR, M. A constituição dos saberes escolares na educação básica. Recife: UFPE, 2007a. (Tese de Doutorado).

. Educação Física numa Proposta Pedagógica em Ciclos de Aprendizagem. In: Revista Brasileira de Ciências do Esporte, Campinas, V. 28, n.2, p.85-99, janeiro. 2007 b.

Recebido em: 29/01/2010

Revisado em: 23/04/2010

Aprovado em: 18/08/2010

\section{Endereço para correspondência}

m.souzajr@uol.com.br

Marcílio Barbosa Mendonça de Souza Júnior

Universidade de Pernambuco,

Escola Superior de Educação Física

Departamento do Conhecimento Técnico Científico

Arnóbio Marques, 310 - Campus Universitário - Santo Amaro

50100130 - Recife, PE - Brasil 